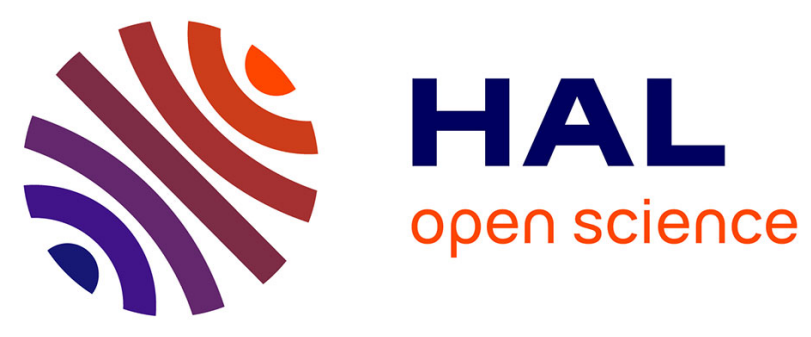

\title{
Selection bias in a population survey with registry linkage: potential effect on socioeconomic gradient in cardiovascular risk
}

Elisabeth Strandhagen, Christina Berg, Lauren Lissner, Leyla Nunez, Annika Rosengren, Kjell Torén, Dag S. Thelle

\section{To cite this version:}

Elisabeth Strandhagen, Christina Berg, Lauren Lissner, Leyla Nunez, Annika Rosengren, et al.. Selection bias in a population survey with registry linkage: potential effect on socioeconomic gradient in cardiovascular risk. European Journal of Epidemiology, 2010, 25 (3), pp.163-172. 10.1007/s10654010-9427-7 . hal-00562277

\section{HAL Id: hal-00562277 \\ https://hal.science/hal-00562277}

Submitted on 3 Feb 2011

HAL is a multi-disciplinary open access archive for the deposit and dissemination of scientific research documents, whether they are published or not. The documents may come from teaching and research institutions in France or abroad, or from public or private research centers.
L'archive ouverte pluridisciplinaire HAL, est destinée au dépôt et à la diffusion de documents scientifiques de niveau recherche, publiés ou non, émanant des établissements d'enseignement et de recherche français ou étrangers, des laboratoires publics ou privés. 


\title{
Selection bias in a population survey with registry linkage: potential effect on socioeconomic gradient in cardiovascular risk
}

\author{
Elisabeth Strandhagen - Christina Berg • Lauren Lissner • Leyla Nunez • \\ Annika Rosengren · Kjell Torén · Dag S. Thelle
}

Received: 17 July 2009/ Accepted: 16 January 2010/Published online: 3 February 2010

(C) Springer Science+Business Media B.V. 2010

\begin{abstract}
Non-participation in population studies is likely to be a source of bias in many types of epidemiologic studies, including those describing social disparities in health. The objective of this paper is to present a nonattendance analysis evaluating the possible impact of selection bias, when investigating the association between education level and cardiovascular risk factors. Data from
\end{abstract}

E. Strandhagen $(\bowtie) \cdot$ L. Lissner $\cdot$ L. Nunez $\cdot$ D. S. Thelle School of Public Health and Community Medicine, Sahlgrenska Academy, University of Gothenburg, Box 454, 40530

Gothenburg, Sweden

e-mail: elisabeth.strandhagen@gu.se

L. Lissner

e-mail: lauren.lissner@medfak.gu.se

L. Nunez

e-mail: leyla.nunez@oc.gu.se

C. Berg

Department of Food, Health and Environment, University of Gothenburg, Box 320, 40530 Gothenburg, Sweden

e-mail: christina.berg@ped.gu.se

\section{A. Rosengren}

Department of Emergency and Cardiovascular Medicine, Sahlgrenska Academy, University of Gothenburg, Floor 2/CK, SU/Östra, 41685 Gothenburg, Sweden

\section{K. Torén}

School of Public Health and Community Medicine, Sahlgrenska Academy, University of Gothenburg, Box 414, 40530

Gothenburg, Sweden

e-mail: kjell.toren@amm.gu.se

D. S. Thelle

Department of Biostatistics, Institute of Basic Medical Sciences, University of Oslo, Oslo, Norway

e-mail: d.s.thelle@medisin.uio.no the INTERGENE research programme including 3,610 randomly selected individuals aged 25-74 (1,908 women and 1,702 men), in West Sweden were used. Only $42 \%$ of the invited population participated. Non-attendance analyses were done by comparing data from official registries (Statistics Sweden) covering the entire invited study population. This analysis revealed that participants were more likely to be women, have university education, high income, be married and of Nordic origin compared to nonparticipants. Among participants, all health behaviours studied were significantly related to education. Physical activity, alcohol use and breakfast consumption were higher in the more educated group, while there were more smokers in the less educated group. Central obesity, obesity and hypertension were also significantly associated with lower education level. Weaker associations were observed for blood lipids, diabetes, high plasma glucose level and perceived stress. The socio-demographic differences between participants and non-participants indicated by the register analysis imply potential biases in epidemiological research. For instance, the positive association between education level and frequent alcohol consumption, may, in part be explained by participation bias. For other risk factors studied, an underestimation of the importance of low socioeconomic status may be more likely.

Keywords Cardiovascular disease risk factors . Education $\cdot$ Selection bias $\cdot$ Socioeconomic status

\section{Introduction}

Social inequality in health remains a major political concern and reducing health inequalities is one of the main challenges within the public health sector in Europe [1]. Even in 
a country like Sweden with a relatively narrow income distribution, there are health differences between social groups [2-5]. Social inequalities in self-reported health have actually been reported to be larger in Sweden compared to some other European countries [6] and inequalities in the risk of coronary heart disease seems to be greater in northern European countries compared with southern Europe [7].

Adequate public health measures tackling these inequalities depend upon valid information and monitoring of the existing health situation including life-style in the population. Monitoring health inequalities can be based upon different sources such as linkage between socio-economic registries to health-related registries and national or local (e.g. regional) health surveys. Sweden is among relatively few countries where personal id numbers can be employed in epidemiological studies. For instance, these registries provide information ranging from sociodemographics to disease status in participants and non-participants. For instance, linkage to a registry enables researchers in Sweden to assess the achieved level of education in survey participants and in the source population.

The validity of the data and the estimates of the strength and direction of health inequality measures will depend upon representative attendance in the study populations with regard to the variables under study. Participation rates in epidemiological studies have declined in recent years [8], and non-participants have been shown to have lower socioeconomic status than participants [9-12]. Such differences as well as unwillingness and lower possibility to participate may result in biased estimates of morbidity, mortality, risk factor levels and their association to social class. Harald et al. [10] demonstrated that non-participants in FINRISK in Finland had higher cardiovascular disease (CVD) mortality than participants, and proposed that the higher risk of CVD death by lower education might be underestimated due to selection bias. The ideal way to assess whether the effect estimates in a survey are systematically deviating from the truth and representing a selection bias would be to compare the information gained in the surveyed sample with the same information from the source population. This however, is usually not possible, but linkage to socio-economic registries may provide insight in the direction and likely magnitude of a probably biased result.

The present study is a cross-sectional assessment of the relation of socioeconomic indicators with cardiovascular risk factors and life-style variables in a population based randomly selected sample. We have used education as a proxy for social class as this is most frequently studied indicator of socioeconomic status, is easy to measure and remains fairly stable through adulthood [13]. A key objective of this paper is to present a non-attendance analysis evaluating possible selection bias, when investigating the association between education level and cardiovascular risk factors, self reported health status, lifestyle and stress and socio-economic indicators in a west Swedish population.

\section{Methods}

The INTERGENE research programme

The subjects in this prevalence study were recruited from the INTERGENE study cohort. INTERGENE is a population-based research programme assessing the INTERplay between GENEtic susceptibility, environmental factors, lifestyle, biological and psychosocial background for the risk of chronic diseases, as well as the trends in cardiovascular disease and risk factors in the Västra Götaland Region in the south-western part of Sweden. The survey started in April 2001 and continued until the end of 2004. The INTERGENE study population consists of three subgroups: coronary heart disease (CHD) patients, their first degree relatives, and a population-based randomly selected sample aged 25-74 years living in the region. Details of this study have been published by Berg [14-16].

\section{Study procedure}

The selected individuals in the population-based sample received a postal invitation and information about the study. On the screening day they gave their written consent, underwent a clinical examination, and filled in questionnaires which were checked by a research nurse. The clinical examination included measures of blood pressure using an inflationary oscillometric blood pressure apparatus (Omron 711 Automatic IS), body weight and height (measured to the nearest $0.1 \mathrm{~kg}$ and centimetre with the subjects in light clothing and without shoes), waist (measured at a level midway between the lower rib margin and iliac crest) and hip circumference (the maximum perimeter over the buttocks), ECG, heart rate and biometric impedance. Blood samples were collected after 4-h fast, into tubes containing $0.1 \%$ EDTA for immediate serum lipid (total cholesterol, triglycerides, HDL-cholesterol), and plasma glucose analysis. Serum total cholesterol (TC) and triglyceride concentrations were determined by using enzymatic assays. Serum HDL-C concentrations were measured after dextran sulphate-magnesium precipitation of apoB-containing lipoproteins. LDL cholesterol levels were estimated for all subjects with triglyceride levels under $4.00 \mathrm{mmol} / \mathrm{L}$, using the Friedewald equation. In order to be classified as participants subjects were required to have valid measures of weight, height and blood pressure. 
Cardiovascular risk markers, lifestyle indicators and socioeconomic factors

The prevalence of elevated cardiovascular risk factors is based upon the European guidelines on cardiovascular disease prevention and World Health Organisation [17, 18]. The frequency of the following cardiovascular risk factors was studied:

- high serum triglycerides: $>1.7 \mathrm{mmol} / \mathrm{L}$

- low HDL cholesterol: men $<1.0 \mathrm{mmol} / \mathrm{L}$, women $<1.2 \mathrm{mmol} / \mathrm{L}$

- high LDL cholesterol: $>3 \mathrm{mmol} / \mathrm{L}$

- high p-glucose: $\geq 6.1 \mathrm{mmol} / \mathrm{L}$

- hypertension: $\geq 140 / 90$ or treatment

- high waist hip ratio: men $>1.0$, women $>0.85$

- obesity: Body Mass Index $\geq 30$

A number of self-reported variables on health status, socioeconomic status, life style, and education were ascertained through a questionnaire. Education alternatives were primary and middle school only, different forms of high school (gymnasium), university education, or other education. These alternatives were collapsed into two categories, lower and higher education. Higher education was defined as any university degree. The other variables and response categories used in this prevalence study are listed below:

- self-reported diabetes, debut after age 30 , yes/no

- poor self-rated health: level 3-4 (fair or poor vs. very good or good)

- current smoker, yes/no

- leisure time physical inactivity: lowest level of 4 categories (e.g. passive leisure time, most time spent reading, watching $\mathrm{TV}$, computer, movies or other)

- frequent alcohol intake: strong beer, wine or spirits $\geq 3$ t/week, yes/no

- stress: two highest levels of 6 categories (continual stress during the last year or continual stress during the last 5 years at home and/or at work)

- regularly skipping breakfast, yes/no

- small economic buffer: not able to, in 1 week, obtain $1,500 €$ if necessary, yes/no

- economic imbalance: continuous problems with running expenses, yes/no

- unmarried, yes/no

- unemployed, yes/no

\section{Registry data}

Information on age, gender, education, income, civil status and country of origin was provided by Statistics Sweden for both participants and non-participants in the INTERGENE programme. The individual's unique 10-digit personal identification numbers were used to link the INTERGENE file with the official registry in order to produce anonymous tables comparing participants and non-participants with regard to the above mentioned characteristics. For the purposes of this study data was obtained for the year 2002. It was not possible to validate the self-reported data against the official data as the information obtained from Statistics Sweden was anonymous at group level. The available demographic data was divided into sex and agegroup categories using age of the participants and nonparticipants in 2002. This allowed us to estimate the proportion of "exposed" subjects in the source population who actually participated in the study sample.

Statistical methods

The statistical analyses were performed using Statistical Analysis Software version 9.1 (SAS Institute Inc., Cary, NC, USA.). Participants and non-participants were compared with regard to available registry data using Pearson chi-square test. All analyses were stratified by sex. A univariate (model 1) and a sex and age-group adjusted (model 2) logistic regression model were used to estimate the effect of each of the registry variables on the odds of participating and non-participating. A two-way interaction between sex and age-group was also included in an additional model, but the results did not differ significantly from the results in model 2, so the interaction factor was left out. Age-adjusted prevalence for women and men separately was generated for each cardiovascular risk factor and the self-reported health status and social characteristics for the low and high education groups using PROC GLM. Logistic regression analyses stratified by sex were used to estimate age-adjusted odds ratios (OR) and corresponding 95\% confidence intervals (CI) of the prevalence estimates. In Tables 3 and 4, age adjustment was done by including age as a linear predictor in the logistic regression equation.

Subjects classified as participants but with missing data on individual variables were excluded from analyses, when needed. All tests were two-sided, with a $P$-value of 0.05 or less considered statistically significant.

\section{Results}

Non-attendance analyses, registry data

A total of 8,820 individuals were invited to participate in the study, of whom 194 were found to be deceased, had moved to another part of the country, another country or had an unknown address. Of the remaining 8,626 eligible individuals 3,610 (1,908 women and 1,702 men) participated yielding a participation rate of $41.9 \%$ (Fig. 1). 
INTERGENE cohort selection, $n=8820$

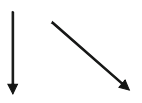

Not eligible, $n=194$

Called, $\mathrm{n}=8626$

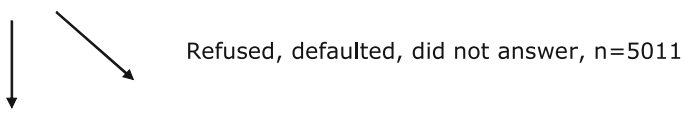

Participants, $\mathrm{n}=3615$

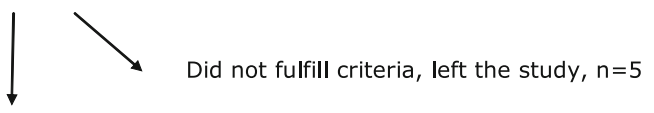

Cohort, $n=3610(41.9 \%)$

Fig. 1 Flow chart for the INTERGENE study cohort

The left columns of Table 1 show participation in the survey stratified by gender and age. Participation was consistently more frequent among women than men across all age-groups except for subjects above 65 years. Participants were older than the non-participants. The right columns are based upon information from the registry (Statistics Sweden) and show frequency of university education in: (1) all eligible individuals and: (2) in participants. Comparison between these columns reveals that the frequency of university education was higher in participants than in the study population across all age groups in both sexes.

Table 2 confirms that attendance was significantly more likely among subjects with more education (OR 1.42, 95\% CI 1.29-1.56) and high income (OR 2.57, 95\% CI 2.232.97), even after adjustment for age and sex. Participation was also higher in subjects from Nordic countries (OR 1.8,
95\% CI 1.31-1.56) and subjects who were married (OR 1.43 95\% CI 1.31-1.56). Participation was lower in the city of Gothenburg than in the rest of Western Sweden, which is a more rural area $(39.7 \%$ vs. $44.0 \%, P<0.0001)$, not shown.

Cardiovascular risk factors in relation to education level, survey data

Among attendees, a number of CVD risk factors showed a favourable pattern with increasing education level. The adjusted ORs and 95\% CIs for the different cardiovascular risk factors, and lifestyle and socio-economic markers according to level of education are shown in Table 3 for women and 4 for men. The upper parts of Tables 3 and 4 show the following objectively measured risk factors to be less favourable in the lower education group: high serum triglycerides (men only), low HDL and high LDL cholesterol (women only), hypertension, high waist-hip ratio and obesity. The lower portions of the tables show that lower education level is associated with poor self-rated health, smoking, low physical activity, abstaining from breakfast, less frequent alcohol intake and small economic buffer.

In Fig. 2 (left panel) we illustrate how low alcohol intake appears to be associated with less education among participants. In women, around half as many of those in low-income category reported three or more drinking occasions per week, resulting in $\mathrm{OR}=0.47$ (95\% CI 0.32-0.67). A similar association was seen for men: $\mathrm{OR}=0.62$ (95\% CI 0.46 $0.83)$. The right panel shows how this biased result could occur, if those with low education and frequent alcohol consumption were less likely to participate. If the true number of individuals in this category is higher than observed, the OR will shift to the right, in the direction of the null.
Table 1 Participation by age and sex based on survey data (left columns), and percentage with university education among: (1) all eligible individuals and: (2) study participants,) based on registry data (missing information, $n=181$; right columns)

\begin{tabular}{|c|c|c|c|c|}
\hline & \multicolumn{2}{|c|}{ Participation in survey data } & \multicolumn{2}{|c|}{ Education level in registry data } \\
\hline & Eligible $(n)$ & $\begin{array}{l}\text { Participants } \\
n(\%)\end{array}$ & $\begin{array}{l}\text { (i) Eligible with university } \\
\text { education, } n(\%)\end{array}$ & $\begin{array}{l}\text { (ii) Participants with } \\
\text { university education, } \\
n(\%)\end{array}$ \\
\hline \multicolumn{5}{|c|}{ Women (age) } \\
\hline $25-34$ & 883 & $247(31.5)$ & $328(42.6)$ & $126(52.5)$ \\
\hline $35-44$ & 1,052 & $415(39.5)$ & $406(38.8)$ & $173(41.6)$ \\
\hline $45-54$ & 925 & $420(45.4)$ & $327(35.5)$ & $165(39.4)$ \\
\hline $55-64$ & 838 & $466(55.6)$ & $227(27.4)$ & $144(31.0)$ \\
\hline$>65$ & 694 & $360(51.9)$ & $103(16.2)$ & $71(20.6)$ \\
\hline Total & 4,292 & $1,908(44.5)$ & $1,391(32.4)$ & $679(36.0)$ \\
\hline \multicolumn{5}{|c|}{ Men (age) } \\
\hline $25-34$ & 794 & $198(24.9)$ & $291(37.4)$ & $88(46.8)$ \\
\hline $35-44$ & 1,058 & $351(33.1)$ & $367(35.3)$ & $144(41.6)$ \\
\hline $45-54$ & 1,015 & $377(37.1)$ & $315(31.0)$ & $125(32.8)$ \\
\hline $55-64$ & 878 & $458(52.2)$ & $239(27.2)$ & $129(27.8)$ \\
\hline$>65$ & 783 & $318(54.5)$ & $83(15.8)$ & $57(19.6)$ \\
\hline Total & 4,329 & $1,702(39.3)$ & $1,295(30.6)$ & $543(32.5)$ \\
\hline
\end{tabular}


Table 2 Registry data on participants and non-participants of 8,621 men and women aged 25-74 years enrolled the Intergene cohort

\begin{tabular}{|c|c|c|c|c|c|}
\hline & \multirow{2}{*}{$\begin{array}{l}\text { Participants }(n=3610)^{*} \\
n(\%)\end{array}$} & \multirow{2}{*}{$\begin{array}{l}\text { Non-participants }(n=5011)^{*} \\
n(\%)\end{array}$} & \multicolumn{3}{|c|}{ Odds of participation response vs. non-response } \\
\hline & & & OR & $95 \% \mathrm{CI}$ & $P$-value \\
\hline Sex & & & Model $1 * *$ & & \\
\hline Male & $1,702(47.1 \%)$ & $2,626(52.4 \%)$ & Reference & & \\
\hline Female & $1,908(52.9 \%)$ & $2,385(47.6 \%)$ & 1.23 & $(1.13-1.35)$ & $<0.0001$ \\
\hline \multicolumn{6}{|l|}{ Age group (years) } \\
\hline $25-34$ & $431(11.9 \%)$ & $1,132(22.6 \%)$ & Reference & & \\
\hline $35-44$ & $763(21.1 \%)$ & $1,345(26.8 \%)$ & 1.49 & $(1.29-1.72)$ & $<0.0001$ \\
\hline $45-54$ & $802(22.2 \%)$ & $1,144(22.8 \%)$ & 1.85 & $(1.61-2.14)$ & $<0.0001$ \\
\hline $55-64$ & $932(25.8 \%)$ & $792(15.8 \%)$ & 3.11 & $(2.68-3.60)$ & $<0.0001$ \\
\hline$>65$ & $682(18.9 \%)$ & $598(11.9 \%)$ & 2.97 & $(2.54-3.48)$ & $<0.0001$ \\
\hline Education & & & Model 2** & & \\
\hline Lower education & $2,332(65.6 \%)$ & $3,422(70.0 \%)$ & Reference & & \\
\hline University education & $1,222(34.4 \%)$ & $1,464(30.0 \%)$ & 1.42 & $(1.29-1.56)$ & $<0.0001$ \\
\hline \multicolumn{6}{|l|}{ Income $^{\mathrm{a}}$} \\
\hline Quartile I & $407(11.3 \%)$ & $947(19.7 \%)$ & Reference & & \\
\hline Quartile II & $836(23.3 \%)$ & $1,185(24.6 \%)$ & 1.71 & $(1.47-1.98)$ & $<0.0001$ \\
\hline Quartile III & $760(21.2 \%)$ & $1,011(21.1 \%)$ & 2.02 & $(1.73-2.37)$ & $<0.0001$ \\
\hline Quartile IV & $1,587(44.2 \%)$ & $1,667(34.6 \%)$ & 2.57 & $(2.23-2.97)$ & $<0.0001$ \\
\hline \multicolumn{6}{|l|}{ Civil status } \\
\hline Unmarried & $1,451(40.2 \%)$ & $2,638(52.9 \%)$ & Reference & & \\
\hline Married & $2,154(59.8 \%)$ & $2,351(47.1 \%)$ & 1.43 & $(1.31-1.56)$ & $<0.0001$ \\
\hline \multicolumn{6}{|l|}{ Native country } \\
\hline Not Nordic countries & $305(8.5 \%)$ & $821(16.5 \%)$ & Reference & & \\
\hline Nordic countries $^{\mathrm{b}}$ & $3,300(91.5 \%)$ & $4,168(83.5 \%)$ & 1.98 & $(1.72-2.28)$ & $<0.0001$ \\
\hline
\end{tabular}

Odds of participation according to age, sex and socioeconomic variables

${ }^{a}$ Quartiles defined by Statistics Sweden: Quartile I: Women: under 10,000 €/year; Men: under 15,000 €/years. Quartile II: Women: 10,00014,999 €/year; Men: 15,000-24,999 €/years. Quartile III: Women: 15,000-19,999 €/year; Men: 25,000-29,999 €/years. Quartile IV: Women: over 20,000 €/year; Men: over 30,000 €/years

b Sweden, Norway, Denmark, Finland or Iceland

* Numbers in each category may not add to total due to missing values

** Model 1: univariate logistic regression; Model 2: Sex and age group adjusted logistic regression

$\mathrm{OR}=$ odds ratio $\mathrm{CI}=$ confidence interval; $\mathrm{NS}=$ non significant

The distribution of risk factors by sex, age and level of education is given in the appendix. Generally, individuals with low education had a more unfavourable cardiovascular risk profile compared to individuals with university education.

\section{Discussion}

Cross-sectional studies serve two major purposes: to describe the prevalence of clearly defined characteristics; and/or to assess associations aiming at generating hypothesis to be addressed in other types of studies. Both objectives are highly sensitive to attendance and may therefore be biased. The second aim however may be more robust and less affected by low attendance. This will depend upon the (dis)similarities of the fractions of the exposed and un-exposed as well as affected and un-affected of the source population actually included in the final study sample.

In our survey the non-participants were more likely to be young, men, unmarried, less educated, of lower income group, and of foreign origin, consistent with other studies $[11,12]$. This study also confirms that high education is associated with lower levels of some cardiovascular risk factors [5]. We have shown significant differences for many of the risk factors between the two educational groups, with similar patterns in both sexes. One clear finding is that the differences in CVD risk factors measured by objective means (blood lipids, blood glucose and between high and low educated) were minor compared to the lifestyle indicators assessed via the questionnaires. This may be due to an information bias as individuals with high versus low education may interpret and answer the questionnaire in 
Table 3 Age adjusted prevalence and age adjusted odds ratio (OR) for cardiovascular risk factors and other socioeconomic indicators, according to education level, in women $(n=1,896)$

\begin{tabular}{|c|c|c|c|}
\hline Risk factor $*$ & $\begin{array}{l}\text { Low education level } \\
n=1,250 \\
\%(95 \% \text { CI })\end{array}$ & $\begin{array}{l}\text { University education } \\
n=646 \\
\%(95 \% \text { CI })\end{array}$ & $\begin{array}{l}\text { Low education vs. } \\
\text { university educatio } \\
\text { OR }(95 \% \mathrm{CI})\end{array}$ \\
\hline \multicolumn{4}{|l|}{ Objectively measured } \\
\hline High serum triglycerides & $16.8(14.7-19.0)$ & $14.3(11.3-17.4)$ & $1.22(0.90-1.66)$ \\
\hline Low HDL cholesterol & $18.0(15.8-20.1)$ & $10.5(7.6-13.5)$ & $1.84(1.35-2.52)$ \\
\hline High LDL cholesterol & $63.4(60.7-66.1)$ & $57.3(53.5-61.0)$ & $1.34(1.07-1.68)$ \\
\hline High p-glucose & $4.5(3.3-5.7)$ & $3.8(2.2-5.5)$ & $1.18(0.66-2.13)$ \\
\hline Hypertension & $26.7(24.4-29.0)$ & $22.5(19.3-25.7)$ & $1.31(1.01-1.70)$ \\
\hline High waist hip ratio & $29.9(27.4-32.3)$ & $20.7(17.2-24.2)$ & $1.69(1.32-2.17)$ \\
\hline Obesity & $17.0(15.1-19.0)$ & $10.3(7.5-13.0)$ & $1.89(1.37-2.60)$ \\
\hline \multicolumn{4}{|l|}{ Self-reported } \\
\hline Diabetes (debut $>30$ years) & $2.2(1.5-3.0)$ & $1.0(0.0-2.0)$ & $2.68(0.92-7.80)$ \\
\hline Poor self-rated health & $29.1(26.7-31.5)$ & $19.1(15.7-22.5)$ & $1.78(1.39-2.27)$ \\
\hline Current smoking & $24.3(22.1-26.5)$ & $10.6(7.5-13.7)$ & $2.60(1.96-3.43)$ \\
\hline Low physical activity & $9.9(8.3-11.5)$ & $6.9(4.6-9.1)$ & $1.47(1.03-2.12)$ \\
\hline No breakfast & $10.2(8.6-11.8)$ & $6.3(4.1-8.6)$ & $1.70(1.16-2.49)$ \\
\hline Frequent alcohol intake & $5.7(4.3-7.2)$ & $11.1(9.0-13.2)$ & $0.47(0.32-0.67)$ \\
\hline Stress & $19.1(16.9-21.3)$ & $19.1(16.0-22.1)$ & $1.00(0.78-1.28)$ \\
\hline Small economic buffer & $18.9(17.0-20.8)$ & $4.8(2.1-7.5)$ & $4.05(2.82-5.81)$ \\
\hline Economic imbalance & $13.0(11.3-14.8)$ & $8.7(6.2-11.2)$ & $1.52(1.11-2.08)$ \\
\hline Unmarried & $10.7(9.0-12.5)$ & $13.0(10.6-15.5)$ & $0.80(0.59-1.08)$ \\
\hline Unemployment & $3.8(2.8-4.8)$ & $2.0(0.7-3.4)$ & $1.78(0.99-3.18)$ \\
\hline
\end{tabular}

* Definitions [17, 18]: high serum triglycerides: $>1.7 \mathrm{mmol} / \mathrm{L}$, low HDL cholesterol: men $<1 \mathrm{mmol} / \mathrm{L}$, women $<1.2 \mathrm{mmol} / \mathrm{L}$, high LDL cholesterol: $>3 \mathrm{mmol} / \mathrm{L}$, high plasma glucose: $\geq 6.1 \mathrm{mmol} / \mathrm{L}$, hypertension: $\geq 140 / 90$ or diagnosis or treatment, high waist hip ratio: Men $>1.0$, women $>0.85$, obesity: Body Mass Index $\geq 30$, frequent alcohol intake: strong beer, wine and spirits $\geq 3$ t/week, Small economic buffer: no ability to, in 1 week, obtain 1,500 $€$ if necessary, Economic imbalance: problem with running expenses

different ways [19]. However, it should be emphasized that blood pressure and different measures of obesity, which are objectively assessed, also varied strongly, and corresponded with the life style habits in this study [16].

One of the strongest education gradients involved frequent alcohol intake, which was far less commonly reported in the less educated group. The observed effect estimate of OR equal to 0.47 for women would indicate a negative bias if there is no effect of education on alcohol consumption. This possible bias due to a skewed distribution of the participants regarding self reported alcohol intake (see methods for definition) and education level is illustrated in Fig. 2. The present result might occur if those with low education and frequent alcohol consumption (a) and/or high education and low alcohol consumption (d) were less likely to attend the study (selection bias) than the two other groups as displayed in the two by two table. If so, the magnitude of the fractions of attendees in the four groups differs from the corresponding fractions in the underlying source population.

An odds ratio closer to 1 could be achieved by increasing the participation of those subjects characterized by (a) and/or (d). It was seen from the registry data that the attendees had a higher education level than the non-attendees and it is known from earlier studies that individuals with high education have a more frequent consumption of alcohol [20,21]. The direction of the effect is consistent with the Danish study [21], but we may have an overestimation of the prevalence of frequent alcohol consumption in those with high education. While it is possible that individuals with lower education are more likely to be binge drinkers with a low frequency of alcohol intake but high consumption at one or two occasions/week, the available data does not allow us to speculate any further.

Limitations and strengths of the study should be noted. Regarding the alcohol example, we have no objective data on participation among drinkers, nor on the actual intake among the participants. Socioeconomic status may influence both whether alcohol drinkers attend and how much they report. On the other hand, this study has the advantage of being based in part on complete data from the population registry. This is a fairly unique resource in Nordic epidemiology, which may be exploited in various ways. In the future, these registries will make it possible to follow up the participating and source populations for cardiovascular events, also included in the Swedish medical registry system. 
Table 4 Age adjusted prevalence and age adjusted odds ratio (OR) for cardiovascular risk factors and other socioeconomic indicators, according to education level, in men $(n=1,685)$

\begin{tabular}{|c|c|c|c|}
\hline Risk factor* & $\begin{array}{l}\text { Low education level, } \\
n=1,225 \\
\%(95 \% \mathrm{CI})\end{array}$ & $\begin{array}{l}\text { University education, } \\
n=460 \\
\%(95 \% \text { CI })\end{array}$ & $\begin{array}{l}\text { Low education vs. } \\
\text { university education } \\
\text { OR }(95 \% \mathrm{CI})\end{array}$ \\
\hline \multicolumn{4}{|l|}{ Objectively measured } \\
\hline High serum triglycerides & $32.8(30.0-35.5)$ & $24.8(20.2-29.3)$ & $1.49(1.14-1.94)$ \\
\hline Low HDL cholesterol & $18.0(15.7-20.3)$ & $18.6(14.8-22.5)$ & $0.96(0.71-1.30)$ \\
\hline High LDL cholesterol & $68.9(66.1-71.7)$ & $65.4(60.7-70.0)$ & $1.17(0.91-1.51)$ \\
\hline High p-glucose & $10.9(9.1-12.7)$ & $10.5(7.5-13.5)$ & $1.07(0.71-1.61)$ \\
\hline Hypertension & $30.2(27.9-32.6)$ & $23.8(19.9-27.6)$ & $1.56(1.17-2.08)$ \\
\hline High waist hip ratio & $14.4(12.6-16.3)$ & $8.1(5.1-11.2)$ & $2.17(1.42-3.34)$ \\
\hline Obesity & $17.8(15.7-19.8)$ & $9.4(6.0-12.7)$ & $2.17(1.51-3.13)$ \\
\hline \multicolumn{4}{|l|}{ Self-reported } \\
\hline Diabetes (debut after 30 years) & $3.9(2.8-5.0)$ & $3.8(2.0-5.6)$ & $1.05(0.55-2.03)$ \\
\hline Poor self-rated health & $24.5(22.2-26.9)$ & $16.9(13.1-20.8)$ & $1.64(1.23-2.20)$ \\
\hline Current smoking & $18.8(16.7-20.8)$ & $7.9(4.6-11.3)$ & $2.63(1.82-3.81)$ \\
\hline Low physical activity & $13.4(11.6-15.2)$ & $8.0(5.0-11.0)$ & $1.72(1.19-2.50)$ \\
\hline No breakfast & $12.9(11.1-14.7)$ & $8.5(5.5-11.5)$ & $1.61(1.10-2.36)$ \\
\hline Frequent alcohol intake & $13.4(11.4-15.4)$ & $19.8(16.4-23.1)$ & $0.62(0.46-0.83)$ \\
\hline Stress & $14.0(12.1-15.9)$ & $12.6(9.4-15.7)$ & $1.13(0.82-1.56)$ \\
\hline Small economic buffer & $10.6(9.0-12.2)$ & $4.2(1.6-6.8)$ & $2.60(1.61-4.22)$ \\
\hline Economic imbalance & $9.6(7.9-11.2)$ & $9.0(6.3-11.6)$ & $1.08(0.75-1.57)$ \\
\hline Unmarried & $12.1(10.3-14.0)$ & $14.6(11.5-17.6)$ & $0.82(0.60-1.13)$ \\
\hline Unemployment & $3.6(2.6-4.6)$ & $2.0(0.4-3.7)$ & $1.67(0.86-3.25)$ \\
\hline
\end{tabular}

* Definitions [17, 18]: high serum triglycerides: $>1.7 \mathrm{mmol} / \mathrm{L}$, low HDL cholesterol: men $<1 \mathrm{mmol} / \mathrm{L}$, women $<1.2 \mathrm{mmol} / \mathrm{L}$, high LDL cholesterol: $>3 \mathrm{mmol} / \mathrm{L}$, high $\mathrm{p}$-glucose: $\geq 6.1 \mathrm{mmol} / \mathrm{L}$, hypertension: $\geq 140 / 90$ or treatment, high waist hip ratio: men $>1.0$, women $>0.85$, obesity: Body Mass Index $\geq 30$, frequent alcohol intake: strong beer, wine and spirits $\geq 3 \mathrm{t} / \mathrm{week}$, Small economic buffer: no ability to, in 1 week, obtain 1,500 € if necessary, Economic imbalance: problem with running expenses

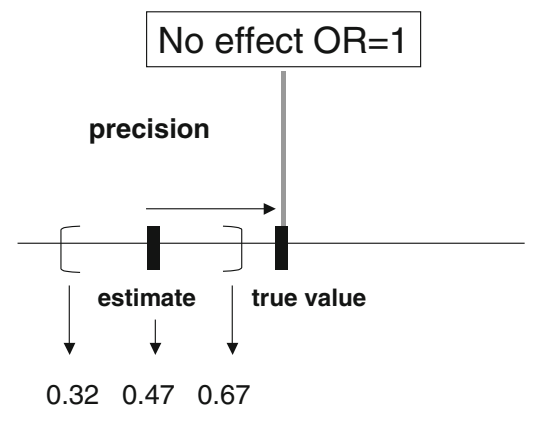

Fig. 2 Left panel shows an illustration of a possibly biased estimate showing a negative effect when the true effect is nil $(\mathrm{OR}=1)$, with 95\% CI (precision) in brackets. Values for women are used as an example. Right panel shows how this biased result will occur, if those

In conclusion, the study confirms the associations between education level and cardiovascular risk and the non-participants are more likely to be young, male, unmarried, have lower education level, lower income, and of foreign origin. Public registries on selected background variables can be used to assess the distribution of attendees and non-attendees, and thereby shed light on the possibility of selection bias.

\begin{tabular}{l|c|c|}
\hline & $\begin{array}{l}\text { Frequent alcohol } \\
\text { consumption }\end{array}$ & $\begin{array}{l}\text { Not frequent } \\
\text { alcohol cons. }\end{array}$ \\
\hline $\begin{array}{l}\text { Low } \\
\text { education level }\end{array}$ & a & b \\
\hline $\begin{array}{l}\text { High } \\
\text { education level }\end{array}$ & c & d \\
\hline
\end{tabular}
OR $=\frac{a / c}{b / d}=\frac{\text { axd }}{b x c}$

with low education and frequent alcohol consumption. a have a tendency to attend to a lower extent. If the true value of (a) is higher than observed, the OR will shift to the right as shown by the arrow in the left panel

Acknowledgments This study was supported by grants from the Västra Götaland County Council, the Swedish Council for Working Life and Social Research, the Swedish Research Council (EpiLife), the Swedish Research Council for Environment and Spatial Planning, and the Swedish Heart and Lung Foundation. There are no conflicts of interest.

\section{Appendix}

See Table 5. 


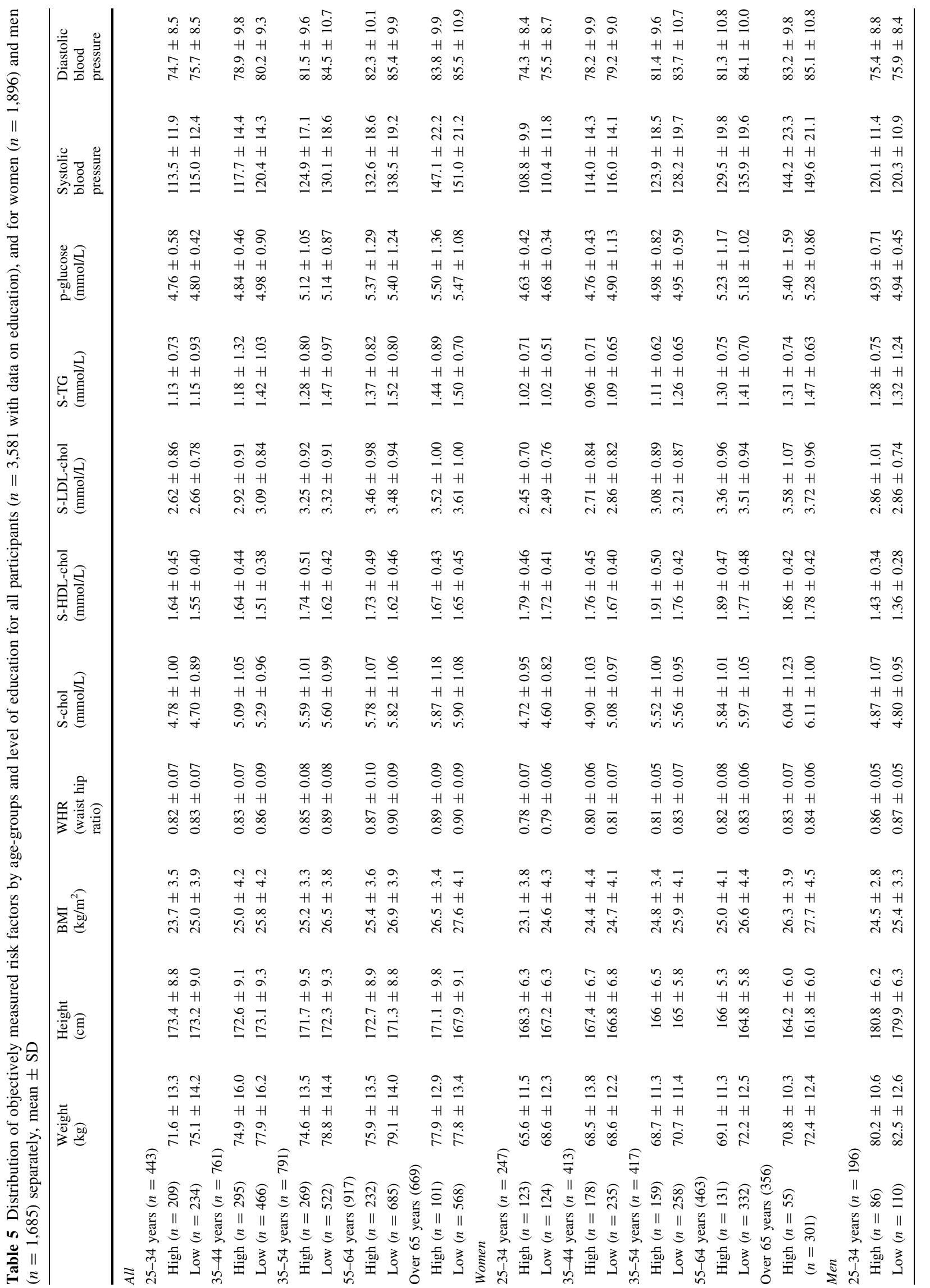




\begin{tabular}{|c|c|c|c|c|c|c|c|}
\hline 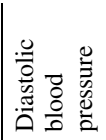 & $\begin{array}{l}\hat{\sigma} \\
+1 \\
0 \\
\dot{\infty}\end{array}$ & $\begin{array}{l}n \\
a \\
+1 \\
n \\
\infty\end{array}$ & $\begin{array}{l}n \\
a \\
+1 \\
\infty \\
\infty\end{array}$ & $\begin{array}{l}n \\
0 \\
+1 \\
m \\
\infty \\
\infty\end{array}$ & $\begin{array}{l}a \\
\infty \\
+1 \\
\hat{\infty} \\
\infty\end{array}$ & $\begin{array}{l}\infty \\
0 \\
+1 \\
0 \\
\dot{0} \\
\infty\end{array}$ & 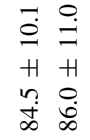 \\
\hline 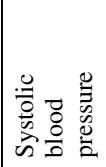 & 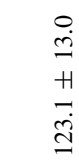 & $\begin{array}{l}\dot{0} \\
\dot{a} \\
H \\
\dot{+} \\
\dot{+}\end{array}$ & 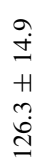 & $\begin{array}{l}m \\
\stackrel{3}{-} \\
+1 \\
0 \\
\stackrel{i}{2}\end{array}$ & 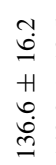 & $\begin{array}{l}n \\
\infty \\
+1 \\
o \\
o \\
\dot{+}\end{array}$ & 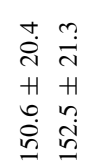 \\
\hline 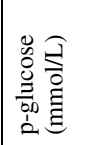 & 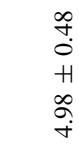 & $\begin{array}{l}8 \\
0 \\
0 \\
H \\
0 \\
\dot{0} \\
\dot{n}\end{array}$ & 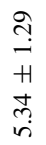 & 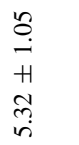 & 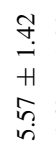 & $\begin{array}{l}\hat{m} \\
\dot{H} \\
\dot{\theta} \\
\dot{n}\end{array}$ & 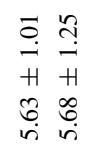 \\
\hline 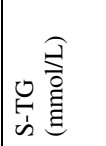 & 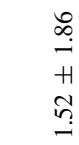 & $\begin{array}{l}\text { İ } \\
+H \\
\stackrel{H}{Z} \\
\end{array}$ & 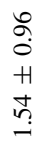 & $\begin{array}{l}0 \\
\stackrel{0}{\Xi} \\
+ \\
+1 \\
0 \\
\stackrel{0}{-}\end{array}$ & $\begin{array}{l}\bar{a} \\
0 \\
H \\
\tilde{f} \\
\dot{\sigma}\end{array}$ & $\begin{array}{l}\hat{\infty} \\
0 \\
+ \\
+1 \\
\widetilde{\sigma} \\
\end{array}$ & 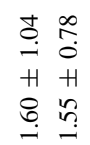 \\
\hline 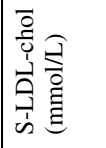 & 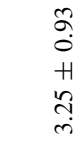 & $\begin{array}{l}\infty \\
\stackrel{0}{0} \\
H \\
\infty \\
\infty \\
\infty\end{array}$ & $\begin{array}{l}\infty \\
0 \\
0 \\
+1 \\
0 \\
\hat{n} \\
0\end{array}$ & \begin{tabular}{l}
+ \\
$\vdots$ \\
0 \\
$H$ \\
I \\
\multirow{y}{c}{}
\end{tabular} & $\begin{array}{l}8 \\
\dot{r} \\
H \\
n \\
n \\
n\end{array}$ & $\begin{array}{l}\dot{0} \\
0 \\
+ \\
+1 \\
0 \\
\dot{0} \\
\dot{0}\end{array}$ & 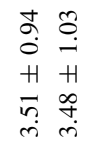 \\
\hline 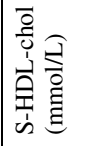 & 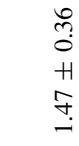 & $\begin{array}{l}\text { तै } \\
0 \\
+1 \\
2 \\
\tilde{2}\end{array}$ & $\begin{array}{l}\hat{n} \\
0 \\
+1 \\
0 \\
0 \\
+\end{array}$ & $\begin{array}{l}0 \\
0 \\
0 \\
+1 \\
\infty \\
+ \\
+\end{array}$ & 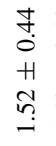 & 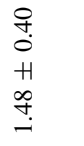 & 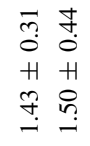 \\
\hline 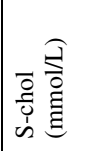 & 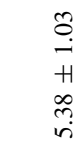 & $\begin{array}{l}8 \\
0 \\
+1 \\
0 \\
i n \\
i n\end{array}$ & $\begin{array}{l}\stackrel{0}{0} \\
\dot{H} \\
+1 \\
\infty \\
\dot{0} \\
\dot{n}\end{array}$ & 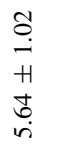 & $\begin{array}{l} \pm \\
\stackrel{ \pm}{H} \\
+ \\
\vec{r} \\
\dot{n}\end{array}$ & $\begin{array}{l}\dot{+} \\
\stackrel{0}{+} \\
H \\
\infty \\
0 \\
\dot{n}\end{array}$ & 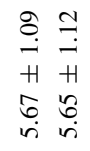 \\
\hline 善 & $\begin{array}{l}8 \\
0 \\
+ \\
+1 \\
0 \\
0 \\
0\end{array}$ & $\begin{array}{l}8 \\
0 \\
H \\
H \\
\sigma \\
\delta\end{array}$ & $\begin{array}{l}2 \\
0 \\
0 \\
+1 \\
\sigma \\
o \\
0\end{array}$ & $\begin{array}{l}8 \\
0 \\
+ \\
+1 \\
\vdots \\
0\end{array}$ & $\begin{array}{l}\hat{0} \\
0 \\
H \\
+ \\
0 \\
0\end{array}$ & $\begin{array}{l}8 \\
0 \\
+1 \\
\vdots \\
\vdots \\
0\end{array}$ & 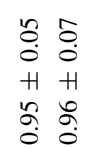 \\
\hline 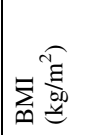 & $\begin{array}{l}\hat{m} \\
+ \\
\dot{y} \\
\ddot{d}\end{array}$ & 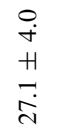 & $\begin{array}{l}\stackrel{+}{r} \\
+ \\
\infty \\
\infty \\
\dot{i}\end{array}$ & $\begin{array}{l}n \\
n \\
H \\
0 \\
\stackrel{n}{n}\end{array}$ & $\begin{array}{l}\infty \\
i \\
H \\
a \\
a \\
\dot{d}\end{array}$ & $\begin{array}{l}m \\
\stackrel{n}{+} \\
+ \\
\stackrel{N}{N}\end{array}$ & 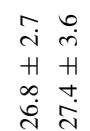 \\
\hline 营 & $\begin{array}{l}\infty \\
\dot{n} \\
+ \\
0 \\
0 \\
\infty \\
0\end{array}$ & $\begin{array}{l}\infty \\
\dot{0} \\
H \\
n \\
\vdots \\
\vdots\end{array}$ & $\begin{array}{l}\stackrel{T}{T} \\
+1 \\
\infty \\
\stackrel{2}{I}\end{array}$ & 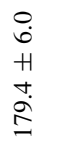 & $\begin{array}{l}a \\
i n \\
H \\
\tilde{0} \\
\infty\end{array}$ & 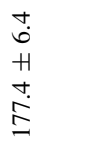 & 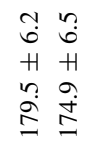 \\
\hline 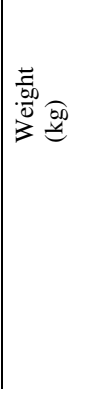 & 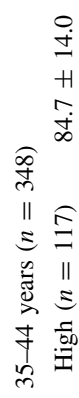 & 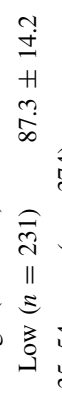 & 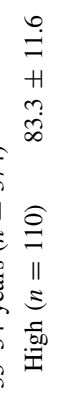 & 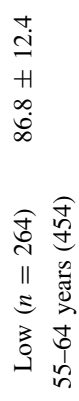 & $\begin{array}{l}\hat{0} \\
+1 \\
0 \\
\infty \\
\dot{0} \\
\widehat{\sigma} \\
11 \\
\Xi \\
500 \\
.00\end{array}$ & 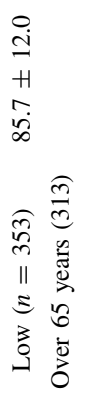 & 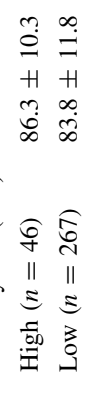 \\
\hline
\end{tabular}

\section{References}

1. Jurczak K, Costongs C. National policies to tackle health inequalities in Europe. Euro Health. 2005;11(2):24-6.

2. Kolegard Stjarne M, Diderichsen F, Reuterwall C, Hallqvist J. Socioeconomic context in area of living and risk of myocardial infarction: results from Stockholm Heart Epidemiology Program (SHEEP). J Epidemiol Community Health. 2002;56(1):29-35.

3. Kuper H, Adami HO, Theorell T, Weiderpass E. Psychosocial determinants of coronary heart disease in middle-aged women: a prospective study in Sweden. Am J Epidemiol. 2006;164(4):34957.

4. Rosvall M, Chaix B, Lynch J, Lindstrom M, Merlo J. Contribution of main causes of death to social inequalities in mortality in the whole population of Scania, Sweden. BMC Public Health. 2006;6:79.

5. Manhem K, Dotevall A, Wilhelmsen L, Rosengren A. Social gradients in cardiovascular risk factors and symptoms of Swedish men and women: the Goteborg MONICA Study 1995. J Cardiovasc Risk. 2000;7(5):359-68.

6. Cavelaars AE, Kunst AE, Geurts JJ, et al. Morbidity differences by occupational class among men in seven European countries: an application of the Erikson-Goldthorpe social class scheme. Int J Epidemiol. 1998;27(2):222-30.

7. Dalstra JA, Kunst AE, Borrell C, et al. Socioeconomic differences in the prevalence of common chronic diseases: an overview of eight European countries. Int J Epidemiol. 2005;34(2):316-26.

8. Morton LM, Cahill J, Hartge P. Reporting participation in epidemiologic studies: a survey of practice. Am J Epidemiol. 2006; 163(3):197-203.

9. Goldberg M, Chastang JF, Leclerc A, et al. Socioeconomic, demographic, occupational, and health factors associated with participation in a long-term epidemiologic survey: a prospective study of the French GAZEL cohort and its target population. Am J Epidemiol. 2001;154(4):373-84.

10. Harald K, Salomaa V, Jousilahti P, Koskinen S, Vartiainen E. Non-participation and mortality in different socioeconomic groups: the FINRISK population surveys in 1972-92. J Epidemiol Community Health. 2007;61(5):449-54.

11. Sogaard AJ, Selmer R, Bjertness E, Thelle D. The Oslo Health Study: The impact of self-selection in a large, population-based survey. Int J Equity Health. 2004;3(1):3.

12. Tolonen H, Dobson A, Kulathinal S. Effect on trend estimates of the difference between survey respondents and non-respondents: results from 27 populations in the WHO MONICA Project. Eur J Epidemiol. 2005;20(11):887-98.

13. Kaplan GA, Keil JE. Socioeconomic factors and cardiovascular disease: a review of the literature. Circulation. 1993;88(4 pt 1): 1973-98.

14. Berg CM, Lissner L, Aires N, et al. Trends in blood lipid levels, blood pressure, alcohol and smoking habits from 1985 to 2002: results from INTERGENE and GOT-MONICA. Eur J Cardiovasc Prev Rehabil. 2005;12(2):115-25.

15. Berg C, Rosengren A, Aires N, et al. Trends in overweight and obesity from 1985 to 2002 in Goteborg, West Sweden. Int J Obes (Lond). 2005;29(8):916-24.

16. Berg CM, Lappas G, Strandhagen E, et al. Food patterns and cardiovascular disease risk factors: the Swedish INTERGENE research program. Am J Clin Nutr. 2008;88(2):289-97.

17. The European Society of Cardiology. European guidelines on cardiovascular disease prevention in clinical practice: executive summary. European Heart Journal. doi:10 1093/eurheartj/ehm 3162007.

18. World Health Organisation. Obesity, preventing and managing the global epidemic. Geneva; 2000. 
19. Laake P, Hjartåker A, Thelle DS, Veierød MB. Epidemiologiske og kliniske forskningsmetoder. Oslo, Norway: Gyldendal Akademisk; 2007.

20. Jacobsen BK. Frequency of alcohol use and the level of education. J Intern Med. 1989;225(6):417-22.
21. Prescott E, Godtfredsen N, Osler M, Schnohr P, Barefoot J. Social gradient in the metabolic syndrome not explained by psychosocial and behavioural factors: evidence from the Copenhagen City Heart Study. Eur J Cardiovasc Prev Rehabil. 2007;14(3):405-12. 